\title{
INFLUÊNCIA DA COMPACTAÇÃO DE UM SOLO ARENOSO NA INFILTRAÇÃO E RETENÇÃO DE CARGA ORGÂNICA DE CHORUME
}

\author{
INFLUENCE OF A SANDY SOIL COMPACTION IN LEACHATE INFILTRATION \\ AND ORGANIC LOADING RETENTION
}

\begin{abstract}
JORGE HAMADA
Engenheiro Civil, Doutor em Hidráulica e Saneamento, Prof. Adjunto da Faculdade de Engenharia - Campus UNESP de Bauru

\author{
Daniela Augusta Nicolielo de Queiroz Pereira Calças \\ Engenheira Civil, Mestre em Engenharia Industrial
}

HERALDO LUIZ GIACHETI

Engenheiro Civil, Doutor em Geotecnia, Prof. Adjunto da Faculdade de Engenharia - Campus UNESP de Bauru
\end{abstract}

Recebido: 22/09/03 Aceito: 07/07/04

\begin{abstract}
RESUMO
Neste estudo avaliou-se o transporte de líquidos e a atenuação da carga orgânica do chorume de aterro sanitário em um solo arenoso fino, compactado com diferentes graus de compactação. Para tanto foram construídas colunas de $1 \mathrm{~m}$ do solo compactado com 75 (natural), 80, 85, 90 e 95\% do Proctor Normal, que foram alimentadas com água e com chorume, sob condições não saturadas. Foram verificadas reduçōes sensíveis na permeabilidade do chorume e na remoção de DQO para as colunas submetidas a graus de compactação igual ou superior a $85 \%$. Os resultados desta pesquisa mostram o grande potencial de uso deste solo compactado, em bases de aterros sanitários de pequeno porte, para a retenção da carga orgânica de chorume.
\end{abstract}

PALAVRAS-CHAVE: Percolação de chorume, solos arenosos, atenuação de carga orgânica.

\begin{abstract}
Water and leachate flow and COD attenuation through a fine sandy soil at different compaction degree were assessed, based on column tests results. Each column was $1.0 \mathrm{~m}$ deep and $0.097 \mathrm{~m}$ in diameter, and the soil was compacted with 75 (natural), 80, 85, 90 and $95 \%$ of Standard Proctor Test, to receive water or sanitary landfill leachate under unsaturated conditions. During the experiment, $C O D$ removal and leachate permeability reduction were very significant for columns with $85 \%$ or higher compaction levels. The results show the high potential of this practice to install simple system in small sanitary landfills, for leachate organic loading retention.
\end{abstract}

KEYWORDS: Leachate flow, sandy soils, organic loading attenuation.

\section{INTRODUÇÃO}

A disposição direta dos resíduos domésticos no solo é a forma corrente de disposição para a maioria dos municípios brasileiros. Apesar de ser uma prática comum de destinação de lixo, até o momento, poucos estudos têm sido conduzidos para avaliar os efeitos provocados principalmente pelo percolado ou chorume, que se infiltra no solo.

Além disso, a maioria dos estudos não fornece subsídios para determinar qualitativamente os efeitos sobre o solo e sobre o próprio líquido que escoa pelo meio poroso. Em função das indefinições encontradas, verifica-se que as condutas adotadas pelos técnicos e aquela estabelecida pela legislação, impōem a adoção de sistemas totalmente confinantes.
A adoção de tais critérios, na realidade, acaba inviabilizando soluçōes para os pequenos municípios geradores do lixo doméstico, principalmente pela obrigatoriedade do emprego de geomembranas para impermeabilização dos respectivos aterros sanitários. Alia-se a esta alternativa, a necessidade de uma operação mais custosa. Por outro lado, quanto maiores são as exigências técnicas, menores serão as possibilidades para que um pequeno município atenda-as integralmente, transformando o que poderia ser um aterro viável em um sistema desordenado de disposição de resíduos.

Uma solução intermediária para restringir o escoamento do chorume para os aquíferos subterrâneos, é a compactação do solo da base, reduzindo sua permeabilidade. Desta forma, o conheci- mento dos processos envolvidos nesse escoamento, através das condiçõos de permeabilidade natural e do solo compactado, diante do escoamento de chorume, permitiria estabelecer quais parâmetros deveriam ser avaliados para viabilizar ambientalmente as instalaçóes, e também definir potencialmente sua capacidade de confinar e atenuar os eventuais impactos sobre o solo.

A compactaçáo do solo local para as bases de aterros constitui uma forma pouco custosa de preparação, resultando na redução da permeabilidade e garantindo um confinamento maior do chorume, apesar de não atingir, algumas vezes, os valores exigidos pelos órgãos ambientais. Neste caso, torna-se fundamental conhecer os mecanismos envolvidos, que permitam avaliar e quantificar eventuais im- 
pactos, assim como estabelecer critérios específicos para execução e operação do sistema de disposição de resíduos. Por outro lado, sabe-se que o uso de geomembranas, sem o devido preparo da base, proteção mecânica ou controle de instalação, pode resultar em sistemas de contenção piores que aqueles constituídos somente por solos compactados.

Como descrito por Daniel (1993), o procedimento de compactação visa a criação de uma barreira protetora, denominada de liner, considerada como revestimento de base e laterais em aterros e obras similares, ou como cobertura final dos aterros. Como revestimento de base, são indicadas quando se deseja retardar ao máximo a migração de contaminantes no solo, saturados ou não, de forma a atenuar a concentração dos contaminantes quando atingirem águas subterrâneas.

McBean et al (1995) e Qasin et al (1994) descrevem que os solos naturais apresentam um sistema complexo e dinâmico em que interagem continuamente os processos físicos, químicos e biológicos. O solo é um sistema heterogêneo e polidisperso de componentes sólidos, líquidos e gasosos, em diversas proporçóes. São também bastante porosos e pela presença de água em seus interstícios, constituem-se como meios solventes. Os solos consistem de substâncias de alta ou baixa solubilidade, de uma grande variedade de compostos orgânicos e de organismos vivos e ainda apresentam um meio favorável no qual ocorrem atividades biológicas complexas de forma simultânea. A força de interação e a predominância de uma reação sobre outra é controlada pelos constituintes específicos do solo. As interações solo-chorume e as reações físicoquímicas envolvidas durante a percolação, resultam na atenuação da carga de contaminantes do chorume. Esse processo de atenuação resulta na redução da concentração de contaminantes durante o respectivo transporte através do solo. As principais formas de atenuação estão incluídas nos seguintes mecanismos básicos: físico (filtração, difusão e dispersão, diluição e absorção); químico (precipitação/dissolução, adsorção/desorção, complexação, troca iônica e reações de redox); e microbiológico (biodegradação aeróbia e anaeróbia).

O objetivo principal deste estudo foi avaliar o transporte de líquidos e a atenuação da carga orgânica do chorume de aterro sanitário nas camadas iniciais do solo e os respectivos efeitos sobre a permeabilidade do solo, considerando-se:
- Base com solo natural

- Bases compactadas com diferentes graus de compactação

- Variação da qualidade do chorume durante o escoamento

\section{METODOLOGIA}

O solo empregado neste estudo pode ser considerado típico daquele que ocorre na região de Bauru, SP, Brasil, e foi classificado texturalmente como areia fina pouco argilosa vermelha. A partir da curva granulométrica, foi obtida a seguinte composição do solo, segundo a escala da ABNT/ NBR-7181/84:

- Areia média: $7 \%$

- Areia fina: $67 \%$

- Silte: $8 \%$

- Argila 18\%

Segundo Agnelli (1997), que também caracterizou o solo da mesma área de amostragem do presente trabalho, o argilomineral predominante na fração fina é a caulinita, com base na baixa capacidade de troca catiônica (CTC), confirmada por microscopia eletrônica de varredura e por difração de raios-x.

Foi montado um conjunto com 5 pares de colunas de percolação em PVC marrom com diâmetro externo de $100 \mathrm{~mm}$, contendo o referido solo em 5 diferentes graus de compactação. A compactação foi controlada pela pesagem de quantidades predeterminadas de solo, que após correção da umidade (massa e umidade conhecidas), formaram camadas de $20 \mathrm{~cm}$ de espessura (volume conhecido), compactadas através de uma haste metálica dotada de uma chapa circular na extremidade, com diâmetro ligeiramente inferior ao interno do tubo. Cada par de colunas apresentou as características mostradas na Tabela 1 . Os coeficientes de permeabilidade mostrados na Tabela 1 foram obtidos em permeâmetros. O esquema de montagem das colunas é apresentado na Figura 1.

Cada par de colunas montadas com mesmo grau de compactação (numeradas de 1 a 5, conforme Tabela 1) recebeu, em princípio, alimentação distinta de água potável (A) e chorume (B) em volumes iguais para todas as colunas. $\mathrm{A}$ alimentação foi semanal, visando distribuir uniformemente o volume equivalente à precipitação média de chuva referente ao semestre mais crítico que correspondia ao período de novembro a abril para a região de Bauru, SP, Brasil. Desta forma o volume semanal foi de
$340 \mathrm{ml}$ para cada coluna (equivalente a uma taxa de 7,6 x 10-3 m/dia), exceto nos casos em que se formava uma lâmina líquida acima de $30 \mathrm{~cm}$, indicativa da redução de permeabilidade do meio. A evolução dos escoamentos foi acompanhada diariamente, através da coleta do efluente das colunas.

As análises químicas realizadas no decorrer desta pesquisa abrangeram os parâmetros DQO, pH, alcalinidade e condutividade elétrica.

\section{RESULTADOS E DISCUSSÃO}

Para a mesma freqüência de alimentação aplicada nas colunas $1 \mathrm{~A}$ a $3 \mathrm{~A}$ verificou-se nos efluentes uma amplitude de resposta volumétrica muito grande para a primeira, e menores e muito semelhantes entre si para as colunas $2 \mathrm{~A}$ e $3 \mathrm{~A}$. Portanto, para o escoamento de água nessas colunas, fica bem clara a distinção entre o solo com massa específica natural (coluna 1) e outros compactados (colunas 2 a 5).

Para as colunas $1 \mathrm{~B}$ e $2 \mathrm{~B}$, verificouse uma grande semelhança na amplitude de resposta (Figuras 2 e 3 ). Por outro lado para as colunas $3 \mathrm{~B}$ e $4 \mathrm{~B}$, nota-se grande diferenciação na resposta das colunas, quando comparada com as colunas $3 \mathrm{~A} \mathrm{e}$ $4 \mathrm{~A}$ (Figuras 4 e 5), evidenciando a influência das características do chorume sobre o escoamento no solo compactado. A resposta dessas duas colunas ao longo do tempo permaneceu praticamente a mesma no período observado.

A diferença fundamental entre as colunas $1 \mathrm{~B}$ a $4 \mathrm{~B}$ pode ser observada na Figura 6, em que se mostra o volume acumulado medido nos respectivos efluentes. Para as colunas 1B e 2B observa-se um comportamento inverso ao esperado, pois a primeira, menos compacta, apresentou como resposta, volumes acumulados menores, denotando maior retenção e dificuldade para o escoamento. Isto se deve, provavelmente, a uma compactação não uniforme das camadas durante o preparo das colunas. Por outro lado, para as colunas $3 \mathrm{~B}$ e $4 \mathrm{~B}$, fica evidente a tendência de redução do escoamento em função da maior compactação do solo.

Durante os ensaios verificou-se que as colunas alimentadas com o chorume alcalino, apresentaram efluentes acidificados antes da saturação de matéria orgânica, como mostrado na Figura 7.

A acidificação destes efluentes deve ter ocorrido, provavelmente, devido à solubilização dos minerais contidos no solo 
Hamada, J., Calças, D. A. N. Q. P., Giacheti, H. L.

Tabela I - Resultados dos ensaios de compactação e permeabilidade com ajuste exponencial de curva para a preparação das respectivas colunas de percolação

\begin{tabular}{cccccccc}
\hline & Ensaios & \multicolumn{4}{c}{$\begin{array}{c}\text { Coeficientes de permeabilidade } \\
(\mathrm{K}) \text { para diferentes leituras }(\mathrm{cm} / \mathrm{s})\end{array}$} & \multicolumn{2}{c}{ Ajuste exponencial } \\
\hline $\begin{array}{c}\text { Massa } \\
\begin{array}{c}\text { específica seca } \\
\left(\mathrm{g} / \mathrm{cm}^{3}\right)\end{array}\end{array}$ & $\begin{array}{c}\text { G.C. } \\
\%\end{array}$ & Colunas & 1 & 2 & 3 & $\begin{array}{c}\mathrm{K}_{\text {ajusad }} \\
(\mathrm{cm} / \mathrm{s})\end{array}$ & $\begin{array}{c}\text { G.C. } \\
\% \\
\text { proctor normal }\end{array}$ \\
\hline 1,90 & 100 & - & $1,8 \times 10^{-6}$ & $1,3 \times 10^{-6}$ & $7,8 \times 10^{-7}$ & $2,2 \times 10^{-6}$ & 98,3 \\
1,89 & 95 & 5A e 5B & $2,0 \times 10^{-6}$ & $3,1 \times 10^{-6}$ & $3,2 \times 10^{-6}$ & $2,6 \times 10^{-6}$ & 97,6 \\
1,77 & 90 & 4A e 4B & $3,8 \times 10^{-5}$ & $3,0 \times 10^{-5}$ & $3,2 \times 10^{-5}$ & $2,0 \times 10^{-5}$ & 88,4 \\
1,72 & 85 & 3A e 3B & $5,3 \times 10^{-5}$ & $4,9 \times 10^{-5}$ & $5,0 \times 10^{-5}$ & $4,7 \times 10^{-5}$ & 84,9 \\
1,66 & 80 & 2A e 2B & $1,0 \times 10^{4}$ & $9,0 \times 10^{-5}$ & $10,0 \times 10^{-5}$ & $1,3 \times 10^{4}$ & 80,8 \\
1,50 & 75 & 1A e 1B & & extrapolado & $2,1 \times 10^{-3}$ & 70,7 \\
1,46 & 70 & - & & extrapolado & $4,1 \times 10^{-3}$ & 68,4 \\
\hline
\end{tabular}

G.C.: Grau de compactação do solo
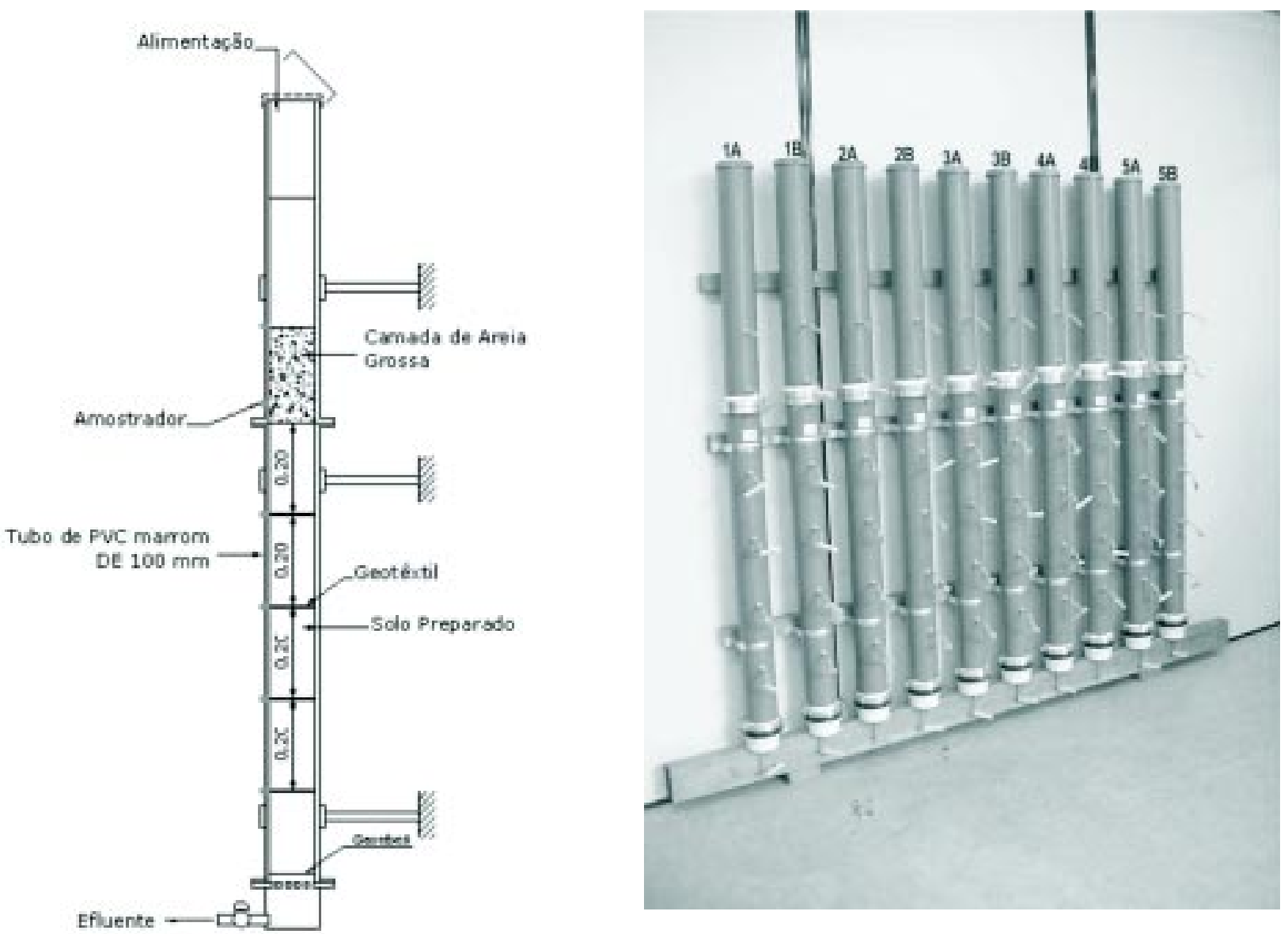

Figura I - Detalhe construtivo das colunas de percolação, que foram dispostas aos pares de forma que (A) refere-se à alimentação com água potável e (B) com chorume 


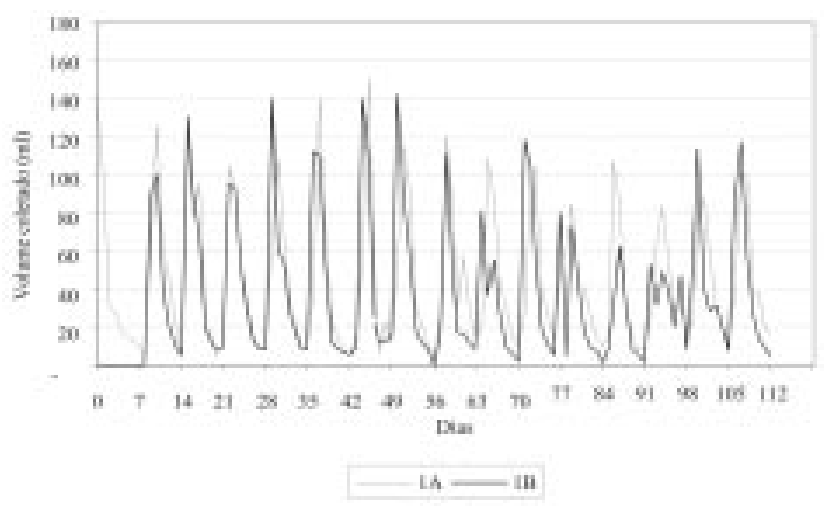

Figura 2 - Comparação entre as colunas IA, alimentada com água e IB alimentada com chorume, considerando-se a resposta volumétrica no efluente

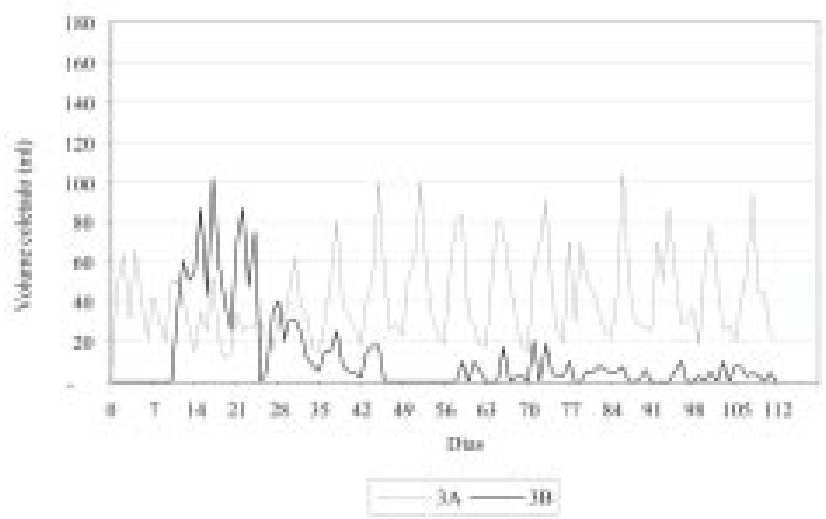

Figura 4 - Comparação entre as colunas 3A, alimentada com água e 3B alimentada com chorume, considerando-se a resposta volumétrica no efluente

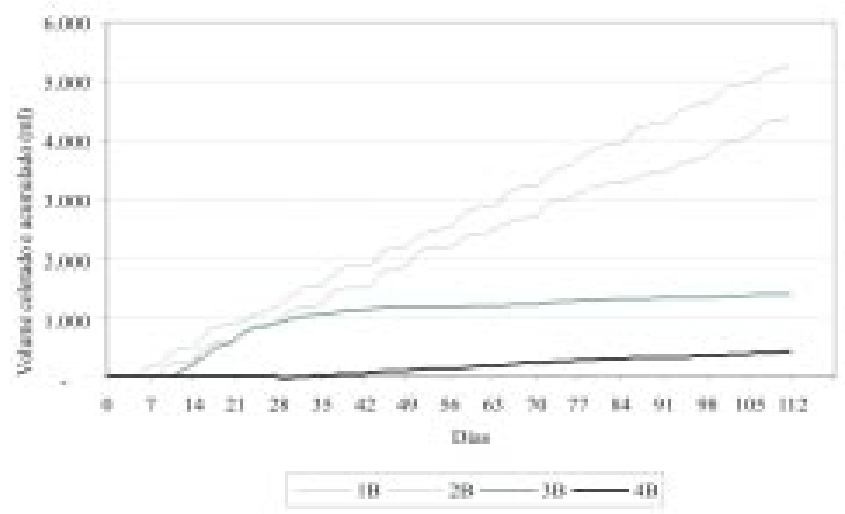

Figura 6 - Volumes acumulados medidos nos efluentes das colunas IB à 4B, alimentadas com chorume

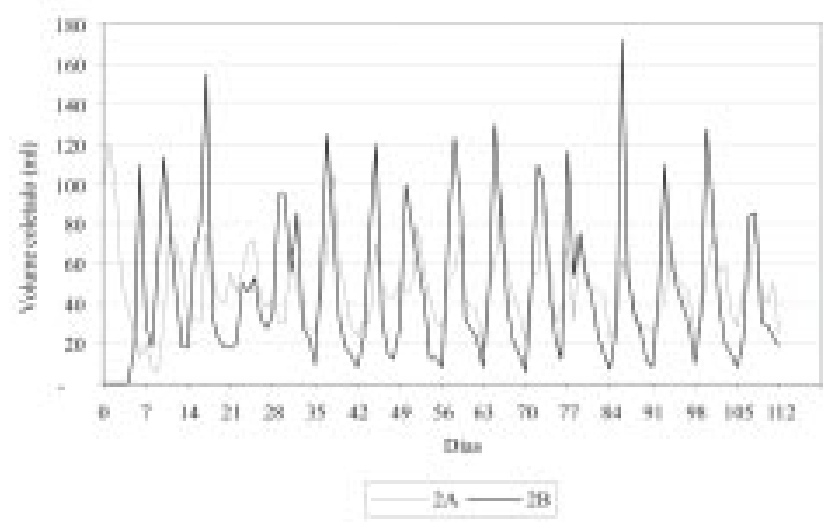

Figura 3 - Comparação entre as colunas $2 \mathrm{~A}$, alimentada com água e 2B alimentada com chorume, considerando-se a resposta volumétrica no efluente

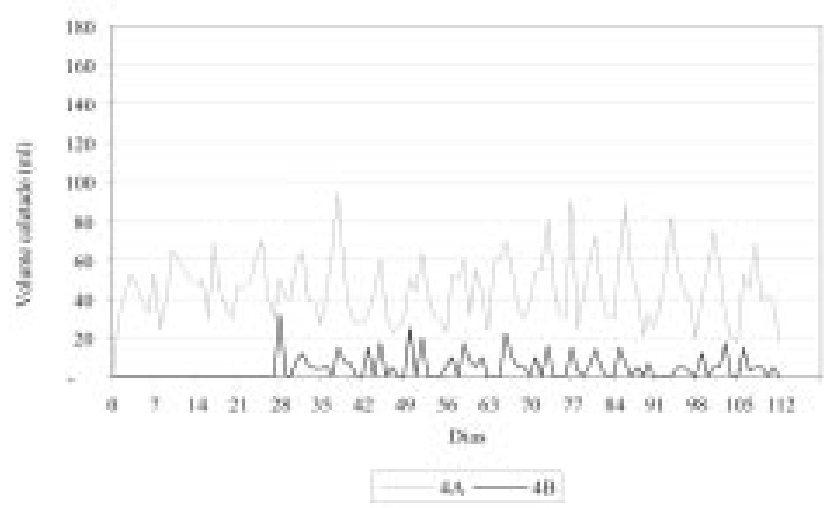

Figura 5 - Comparação entre as colunas 4A, alimentada com água e 4B alimentada com chorume, considerando-se a resposta volumétrica no efluente

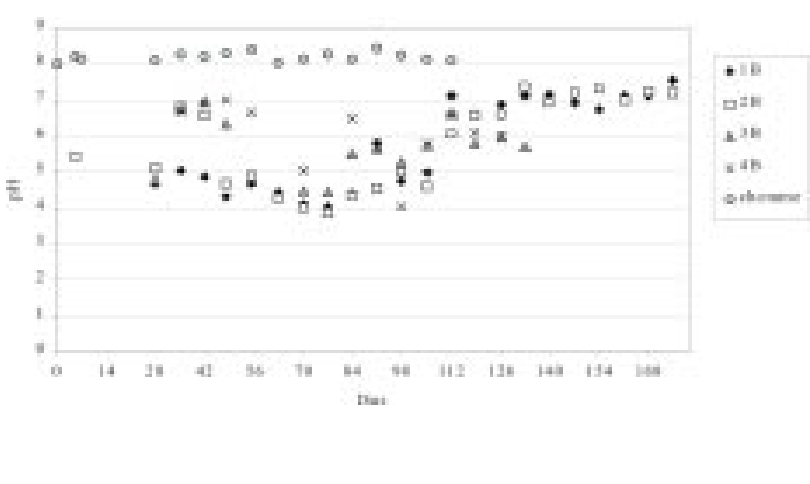

Figura 7 - Valores de pH do chorume bruto e no efluente das colunas de percolação 
solo quando em contato com a solução percoladora, e também pela perda de bases do solo, arrastadas pela água e pelo chorume durante a infiltração. A acidificação do efluente pode ter tido contribuição da matéria orgânica, que tenha sofrido degradação de forma anaeróbia, denotando o surgimento de microorganismos no sistema. Por outro lado, segundo Agnelli (1997), a designação do solo estudado, em relação ao seu pH (valores entre 4 e 5), varia de hiperácido a ácido, fato este que pode ser considerado como o mais relevante para a acidificação do efluente.

$\mathrm{Na}$ Figura 8 observa-se que como as colunas $1 \mathrm{~B}$ e $2 \mathrm{~B}$ têm menor grau de compactação que as colunas 3B, 4B e 5B, não estão mais conseguindo restringir o escoamento do chorume e o aumento da condutividade elétrica está ocorrendo gradativamente. Nota-se que o efluente da coluna 5A, apresentou uma condutividade inicial bastante alta, comparando-se com as demais colunas alimentadas com água, fato que se deve provavelmente, ao longo período que ficou armazenada em contato direto com o solo, solubilizando minerais.

Ao final do período de dois meses verificou-se que os valores de DQO do efluente das colunas $1 \mathrm{~B}$ e $2 \mathrm{~B}$ apresentaram alterações significativas, indicando menor capacidade de retenção de matéria orgânica. Entre o $90^{\circ}$ e o $98^{\circ}$ dia observa-se nestas colunas o aparecimento de sólidos e uma alteração na cor do efluente, acarretando um aumento considerável no valor da DQO. Essa variação brusca fornece indícios de que ocorreu uma saturação do meio, reduzindo drasticamente sua capacidade de retenção de matéria orgânica.

Verifica-se que além da capacidade de remoção de DQO através de retenção, adsorção ou processos oxidativos, uma forma eficiente de atenuação bastante significativa é a crescente colmatação, verificada para as colunas $3 \mathrm{~B}$ e $4 \mathrm{~B}$. Nestas colunas a alimentação praticamente foi interrompida, uma vez que a resposta volumétrica no efluente foi muito pequena, atingindo valores inferiores a $100 \mathrm{ml}$ mensais.

Quando comparados às colunas $1 \mathrm{~B}$ e $2 \mathrm{~B}$, esses resultados demonstram a influência significativa da compactação do solo, pois nestas colunas não se observaram alteraçóes relevantes na resposta volumétrica das alimentaçóes semanais. Desta forma conclui-se, para o experimento realizado, que graus de compactação

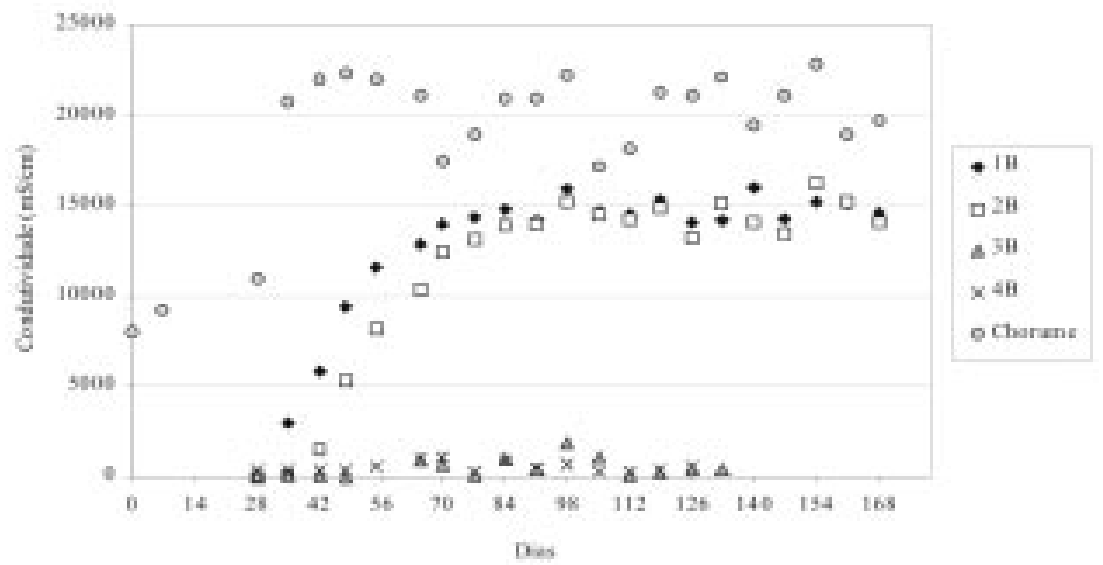

Figura 8 - Valores de condutividade elétrica do chorume bruto e no efluente das colunas de percolação

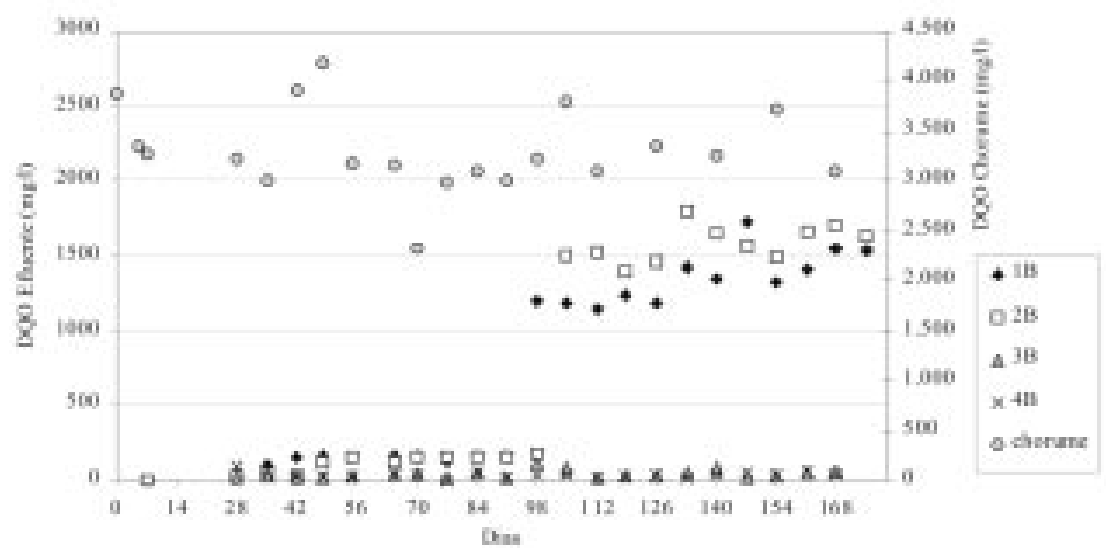

Figura 9 - Valores da DQO do chorume bruto e no efluente das colunas de percolação

acima de $85 \%$ são altamente benéficos para a atenuação de DQO considerando-se o chorume utilizado.

$\mathrm{Na}$ avaliação dos resultados dos ensaios realizados nas colunas $1 \mathrm{~B}$ e $2 \mathrm{~B}$, observa-se um limite bastante claro na capacidade de remoção de DQO, como ilustrado na Figura 9 e mostrado Tabela 2. Para constatar essa capacidade, foi elaborada a Tabela 3, em termos de carga de DQO, considerando-se como limite os dias em que foram observadas elevações abruptas deste parâmetro, em destaque.

Desta forma, um solo com massa específica natural teria a capacidade de retenção de $1,415 \mathrm{~g}$ de DQO por kg de solo seco. Para um grau de compactação de $80 \%$ esta capacidade seria de $1,363 \mathrm{~g}$ de DQO por kg de solo seco, valor próximo ao anterior. Em valores absolutos, isto significa que uma determinada quantidade de solo retém uma quantidade proporcional de DQO.

\section{CONCLUSÕES}

\section{Fluxo de líquidos no solo}

Considerando o escoamento somente de água, diferença marcante foi observada somente para o solo com grau de compactação de $95 \%$, onde houve uma redução significativa da permeabilidade. Para os demais não houve diferenças significativas, exceto na maior amplitude de resposta para o efluente da coluna cujo solo foi compactado à valores de massa específica natural.

Em relação ao escoamento de chorume não foram observadas alterações significativas para as duas colunas com menor grau de compactação (natural e $80 \%$ ), assemelhando-se ao comportamento das primeiras colunas submetidas à alimentação com água. Por outro lado, os solos compactados com graus de 85 e $90 \%$, apresentaram entre si comportamentos semelhantes, com redução cres- 
Tabela 2 - Cargas de DQO aplicadas às colunas de percolação

\begin{tabular}{|c|c|c|c|c|c|c|c|}
\hline \multirow[b]{2}{*}{ Dias } & \multicolumn{2}{|c|}{ Alimentação } & \multirow[t]{2}{*}{$\begin{array}{l}\text { DQO } \\
(\mathrm{mg} / \mathrm{l})\end{array}$} & \multirow{2}{*}{$\begin{array}{c}\text { Carga } \\
\text { de DQO } \\
(\mathrm{g})\end{array}$} & \multirow{2}{*}{$\begin{array}{c}\text { Carga de } \\
\text { DQO } \\
\text { acumulada } \\
(\mathrm{Kg})\end{array}$} & \multicolumn{2}{|c|}{$\begin{array}{l}\text { DQO efluente } \\
(\mathrm{mg} / \mathrm{l})\end{array}$} \\
\hline & $\begin{array}{l}\text { Volume } \\
\text { (ml) }\end{array}$ & $\begin{array}{l}\text { Vol. acumulado } \\
\qquad(\mathrm{ml})\end{array}$ & & & & $\begin{array}{c}\text { Coluna } \\
1 \mathrm{~B}\end{array}$ & $\begin{array}{l}\text { Coluna } \\
2 \mathrm{~B}\end{array}$ \\
\hline 0 & 340 & 340 & & & & & \\
\hline 1 & 340 & 680 & & & & & \\
\hline 7 & 340 & 1.020 & 3.280 & 1,12 & 0,00375 & & \\
\hline 13 & 340 & 1.360 & 3.280 & 1,12 & 0,00487 & & \\
\hline 20 & 340 & 1.700 & 3.280 & 1,12 & 0,00598 & & \\
\hline 27 & 340 & 2.040 & 3.240 & 1,10 & 0,00709 & 19 & 19 \\
\hline 34 & 340 & 2.380 & 3.000 & 1,02 & 0,00811 & 103 & 45 \\
\hline 42 & 340 & 2.720 & 3.920 & 1,33 & 0,00944 & 145 & 31 \\
\hline 48 & 340 & 3.060 & 4.180 & 1,42 & 0,01086 & 162 & 124 \\
\hline 55 & 340 & 3.400 & 3.180 & 1,08 & 0,01194 & 156 & 153 \\
\hline 62 & 340 & 3.740 & 3.180 & 1,08 & 0,01302 & 162 & 128 \\
\hline 69 & 340 & 4.080 & 2.320 & 0,79 & 0,01381 & 163 & 152 \\
\hline 75 & 340 & 4.420 & 2.320 & 0,79 & 0,01460 & 123 & 150 \\
\hline 83 & 340 & 4.760 & 3.100 & 1,05 & 0,01565 & 164 & 154 \\
\hline 90 & 340 & 5.100 & 3.000 & 1,02 & $0,01667^{(1)}$ & 162 & 157 \\
\hline 97 & 340 & 5.440 & 3.240 & 1,10 & $0,01778^{(2)}$ & 1.200 & 174 \\
\hline 104 & 340 & 5.780 & 3.800 & 1,29 & 0,01907 & 1.182 & 1.494 \\
\hline 111 & 340 & 6.120 & 3.100 & 1,05 & 0,02012 & 1.144 & 1.525 \\
\hline
\end{tabular}

(') Saturação de DQO observada para a coluna compactada a 70\% do proctor normal (1B)

( $\left.{ }^{2}\right)$ Saturação de DQO observada para a coluna compactada a $80 \%$ do proctor normal (2B)

Tabela 3 - Características físicas e capacidade limite de retenção de carga de DQO das colunas de infiltração

\begin{tabular}{cccc}
\hline Parâmetro & Unidade & \multicolumn{2}{c}{ Colunas } \\
& & 1 & 2 \\
\hline Carga de DQO acumulada & $\mathrm{kg}$ & 0,01667 & 0,01778 \\
Grau de compactação & $\%$ & 70 & 80 \\
Volume coluna & $\mathrm{m}^{3}$ & 0,00785 & 0,00785 \\
Massa específica do solo seco & $\mathrm{kg} / \mathrm{m}^{3}$ & 1500 & 1660 \\
Massa de solo & $\mathrm{kg}$ & 11,781 & 13,038 \\
Capacidade de retenção por unidade de massa & gDQO/kgSolo & 1,415 & 1,363 \\
\hline
\end{tabular}


cente do fluxo para valores inferiores a $100 \mathrm{ml}$ mensais. Tal fato demonstra suscetibilidade à colmatação do solo compactado estudado com graus maiores ou iguais a $85 \%$, promovida pelas partículas em suspensão e pelo desenvolvimento provável de flocos e películas biológicas. O solo compactado a $95 \%$, não apresentou resposta até o momento, com relação ao escoamento, mostrando que para as condições hidráulicas impostas, não foi possível estabelecer um fluxo para o chorume aplicado.

\section{Capacidade de retenção de carga orgânica}

Com relação ao item mais relevante deste estudo, é possível concluir que o solo em questão apresenta, sob diferentes condições, bom potencial para retenção de carga orgânica de aterros sanitários, apesar de ser classificado texturalmente como arenoso. Ainda, mesmo sob condiçôes de massa específica natural, apresenta características importantes de atenuação, com retenção significativa de matéria orgânica. Sua capacidade de atenuação torna-se mais significante, quando compactado em graus acima de $85 \%$ do Proctor Normal.

Portanto, a aplicabilidade e importância deste solo residem, em princípio, no controle da compactação em termos de energia e de umidade. Quando associado à geosintéticos, este solo pode dispensar, com vantagens econômicas, o uso de argila ou solos argilosos nas bases de aterros sanitários.
Presume-se fortemente que a presença da caulinita na fração fina do solo, embora não seja normalmente a mais indicada para a confecção de liners, tenha um papel fundamental na capacidade de retenção, principalmente quando se efetua a compactação com maior energia para este solo.

Conclui-se, também, que as características ácidas do solo são fundamentais para remoção da elevada alcalinidade do chorume em questão, que ocorre naturalmente, pela neutralização das bases químicas existentes.

\section{Limitações para emprego dos resultados obtidos}

Os resultados obtidos, embora relevantes, devem ser avaliados com cautela quando se vislumbra o emprego deste tipo de solo sob condições de campo. Em um primeiro momento, duas condiçōes deveriam merecer uma avaliação criteriosa: a heterogeneidade do solo e o controle de execução da base.

Porém, o mais importante, é a consideração que os estudos foram realizados sob condições de laboratório e as alimentaçôes de água e chorume foram controladas e de maneira uniforme, com taxas hidráulicas que propiciaram um escoamento em meio não saturado. Para taxas maiores, como ocorre na incidência de chuvas torrenciais e de longa duração, as condiçôes de permeabilidade podem ser alteradas significativamente, resultando em cargas hidráulicas bem acima daquelas aplicadas em laboratório.
Portanto, os resultados merecem estudos complementares, inclusive com aumento da escala e sob condições de campo.

\section{AGRADECIMENTO}

À FAPESP - Fundação de Amparo à Pesquisa do Estado de São Paulo pelos recursos que viabilizaram a execução desta pesquisa.

\section{REFERÊNCIAS}

AGNELLI, N., Comportamento de um Solo Colapsivel Inundado com Líquidos de Diferentes Composições Químicas. Tese de Doutorado. Escola de Engenharia de São Carlos - USP. São Carlos. 1997

DANIEL, D.E. Case histories of compacted clay liners and covers for waste disposal facilities. In: Proc. of the $3^{\text {rd }}$ INTERNATIONAL CONFERENCE ON CASE HISTORIES IN GEOTECHNICAL ENGINEERING, St, Mo., S. Prakash (ed.), p.14071425. 1993.

McBEAN, E.A., ROVERS, F.A., FARQUHAR, G.J. Solid Waste Landfill Engineering and Design. Prentice Hall, Inc. 521 p. 1995.

QASIM, S.R., CHIANG, W. Sanitary Landfill Leachate - Generation, Control and Treatment. Technomic Publishing Co., Inc. 323 p.1994.

Endereço para correspondência:

Jorge Hamada

Rua Martinha Dal Médico, I-35

I 70 I 8- I 50 - Bauru - SP - Brasil

Tel.: (I4) 3226-I535

E-mail: joha@feb.unesp.br

\section{$23^{\circ}$ Congresso Brasileiro de Engenharia Sanitária e Ambiental}

18 a 23 de setembro de 2005

Resumos expandidos: até 30 de outubro de 2005 Centro de Exposições Albano Franco

Campo Grande - MS 